\title{
Sustained participation in open source: A psychological contract approach
}

\author{
Almudena Cañibano \\ ESCP Business School \\ Madrid Campus, Spain \\ acanibano@escp.eu
}

\author{
Daniel Curto-Millet \\ Swedish Center for Digital Innovation \\ Gothenburg University, Sweden \\ daniel.curto-millet $@$ ait.gu.se
}

\author{
Lukas Rojahn \\ ESCP Business School \\ Madrid Campus, Spain \\ lukas.rojahn@edu.escp.eu
}

\begin{abstract}
We propose the use of the psychological contract as an alternative theoretical lens to study sustained participation and engagement in open source, which is often used as an example of new forms of digitized independent work. Psychological contracts are the set of beliefs held by individuals of their personal exchange with an organization and other actors with which they work. While previous literature has tended to study inducements (e.g., intrinsic or extrinsic motivation) on its own, the psychological contract studies the relation between an individual's expected inducements and contributions. If these expectations are unmet, a breach can take place that will affect contributor engagement. We suggest the usefulness of this theory in understanding why and how open source participants decide to stop or reduce their involvement. Participants hold multiple psychological contracts with the project, fellow developers, and users. The findings show that breach can be experienced with all of them either due to unmet contributions or inducements. We suggest further research into such breaches is required to understand their consequences on the sustainability of open source projects.
\end{abstract}

\section{Introduction and background}

Open source software are computer programs that have traditionally been built by volunteers [1]. These volunteers donate their time and effort to collaborate in developing code and documentation, which they make available to other developers who can, in turn, share and modify them. Recent surveys indicate the established role that open source plays in today's economy, with $90 \%$ of IT leaders reporting using open source [2] and contributing £43.1bn yearly to the UK's GDP [3]. Open source development has increased in many countries, with a recent study suggesting that the passing of a French law that promoting open source led to an increase of 600000 yearly contributions [4].
Open source projects have been considered examples of the new and growing forms of digitized and independent work $[5,6]$. Because of its reliance on volunteers, a key recurrent question in open source has been why participants contribute to open source projects [7]. Lerner and Tirole ask [8:198]: "Why should thousands of top-notch programmers contribute freely to the provision of a public good?"

At the heart of this question lies the preoccupation and wonderment about the sustainability of open source [9]. Indeed, definitions of sustainability often depend on the continued decision of contributors to keep participating. A key definition of open source sustainability borrowed from commons ecological studies is whether it is capable to continuously produce value to its stakeholders $[1,10]$. This value can only continuously be produced if there is such participation. It is critical for software projects to be maintained, bugs corrected, libraries updated, otherwise the project's value may become eroded in time [11]. Researchers have thus suggested that sustained participation is necessary for open source to be sustainable [12, 13]. Yet, participants' engagement is often fleeting and we still lack theoretical mechanisms to explain why this so.

To remedy this gap, the literature ha heavily relied on psychological and organizational behaviour theories $[14,15]$, namely self-determination theory (SDT) and social exchange theory, to explain why contributors keep contributing. SDT, in particular, has been used to explain what motivates contributors to participate [16]. According to such studies, open source contributors have high levels of intrinsic motivation, particularly those who prolong their participation beyond the shortterm [17]. Personal enjoyment and learning opportunities are repeatedly cited as motivational drivers [18]. Learning new skills and self-improvement is particularly important, with surveys consistently placing such intrinsic motivation as a key reason for contributing to open source $[19,20]$.

Research has also suggested that more extrinsic motivations also matter for continued participation. 
Work on open source is often a good signal to employers, with participants showing off skills and social capital from their participation in open source communities [21]. Other strong extrinsic motivators are need and use-value (i.e. a developer scratching an itch) [22], gaining status [23], or financial rewards [24]).

Not all participants are likely to share in the same way the resulting gains from their participation [25], with some contributors reaping far less extrinsic benefits than others [26, 27]. Certain performed tasks signal looked-after skills by market actors such as managerial experience [21]. Certain profiles of contributors, then, have little choice but to rely on intrinsic motivations far more than others, if, for example, they do not have social capital to have returns from their participation. Inversely, those contributors who are more socially inserted spend less resources fitting into the community [12], meaning that the potential extrinsic reward is inherently greater to those who are already insiders. Alternatively, those contributors who do not see financial rewards as problematic do not perceive crowding out effects on their intrinsic motivation [24]. Indeed, motivations may differ vastly between contributors since open source projects are made up of highly heterogeneous actors, including firms and their employees, voluntary participants with differing levels of commitment, software users, public institutions, etc. [28], who share their work as part of a community.

The reliance of SDT theories to explain why contributors keep participating [14], may be problematic. First, open source is a complex environment in which mingle hobby-like and commercial interests, making it difficult to parse intrinsic and extrinsic motivations [25]. For example, enjoying learning skills can be both placed as an intrinsic and extrinsic motivation [25]. Second, SDT theories exclusively look at inducements and what participants can obtain from their contributions. Even those more extrinsic drivers that take into account individuals' willingness to contribute to the common good as a motivation [23, 29], still answer the same fundamental question: 'what do I receive from my involvement?' If the rewards are sufficient, then the individuals decide to continue contributing, otherwise, they stop. To our knowledge, this work investigates only why people contribute but overlooks exploring why they stop, latently assuming that the latter is merely the result of contributing conditions not being met.

To circumvent limitations in SDT, an important second research stream aims to explain why contributors sustain their participation building on mechanisms of social exchange theory such as gift culture and reciprocity [30, 31]. Osterloh and Rota [32], intrinsic and extrinsic motivations are not sufficient explanations on their own to understand how open source is sustained, extending Ostrom [33] to propose structural and governance mechanisms which supports such motivational aspects found in open source. In their reading, motivation theory remains important, but voluntary contributions can only be made sense of by looking at the specific open source dynamics that ensure certain behaviors are monitored and rewarded. The way these mechanisms are generally deployed in open source studies presupposes a sharing culture much more calculative than the anthropological studies from which they were inspired [34]. von Krogh et al. [35:1233], for example, defines social exchange as a way in which "individuals form relationships to maximize rewards and minimize costs." There is an expectation in open source that freely contributed code will be protected by mechanisms that ensure that nothing untoward is going to happen [32], giving rise to specific work on governance structures as projects mature [36], while creating a culture that suggests there should be reciprocity [37]. Again, this stream of literature has not specifically delved into why participants stop contributing, focusing mainly and why they do participate.

This paper builds on the insights derived by both these streams to understand specifically why people stop participating. Research often remarks on the peculiarity of open source that many such projects and communities fail [38]. Yet, there has been little research on why projects fail, with studies focusing instead on understanding how successful ones manage to sustain contributions. We propose that people do not stop enjoying learning new skills or other such intrinsic motivations, or that they stop perceiving open source as a good signal for career prospects. Instead, they reflect on whether the expectations they had regarding the exchange between what they put in what they receive are met. One project may meet expectations making them sustain their participation, while another will not. In this sense, the two questions: why do people contribute to open source and why do they stop?, are intimately related. Understanding why people stop contributing to open source sheds light on why they decide to keep contributing. As such, we posit that there is a dynamic relationship between individuals and their decision to continue or stop contributing to open source projects.

To answer these two questions, we analyze the mailing lists of a large open source project over a period of four years, focusing on contributors' narratives regarding their ongoing participation. To do so, we rely on the psychological contract as a theoretical lens. The reminder of the paper is organized as follows. The next section presents the theoretical framework. Section three describes the methods of the study, section four presents the findings and section five discusses them. 
We conclude offering practical implications and acknowledging the limitations of the study.

\section{Theoretical lens}

The psychological contract (PC) is a framework commonly used in the human resource management and organizational behavior literatures. It builds on administrative theory to understand work relationships as cooperative systems [39]. The PC is defined as the set of 'individual beliefs, shaped by the organization, regarding terms of an exchange agreement ... [and] is potentially idiosyncratic and unique to each person who agrees to it' [40:9-10]. Psychological contracts are restricted to individuals; organizations cannot have a PC of their own and are merely the frame within which individuals form theirs [41]. The PC can thus be described as the mental picture that individuals form regarding their personal exchange with their organization. It is the mechanism that allows them to keep track of, on the one hand, the contributions they offer to their organization and, on the other hand, the inducements they receive from their organization [42].

Although the PC lens has been primarily used in the context of employment relationships (i.e. "work that is performed under contractual arrangements and involves material rewards" [43:109]), several authors have pointed out that any relationship involving expectations between parties is subject to the development of a PC $[40,44]$. Although open source participants are generally volunteers who do not have an employment relationship with the project, they arguably develop expectations and beliefs regarding their interaction with different parties that are involved in the development of software.

The PC is a helpful lens through which to investigate sustained participation in open source for several reasons. First, it allows exploring open source participation as an exchange phenomenon in which both contributions and inducements play a role, rather than just inducements (what people get from participating, which is the prevalent approach in the literature).

Contributions have been described as 'payments to the organization' [39:85]. They can take very diverse forms ranging from adequate job performance and low absenteeism [45], to working overtime or being constantly available to work [46]. Inducements are rewards that are offered to the workers [47:1113]. They can be extrinsic (e.g. wages) or intrinsic (e.g. interesting job) [48].

Administrative theory highlights that a situation of imbalance between contributions demanded from the employee and inducements offered to the employee cannot endure, because it will push the organization to change the arrangement or the employee to quit [49].
From a PC perspective, such balance relies on individual perceptions and expectations rather than on objective and measurable facts [50]. In this context, the concept of 'breach' emerges as essential. PC breach is defined as the employee's perception that "the terms of their psychological contracts have not been adequately fulfilled" [51:226]. When breach takes place, the individual no longer believes the other party to uphold their end of the bargain, thus making the exchange unsustainable in the long run. For example, Shaikh and colleagues [52] observed a number of breaches of trust between developers in her research on version control of the Linux kernel, in particular, when a non-free versioning system was introduced.

Second, the PC is a particularly useful framework to understand individual exchanges in which many things are "legitimately expected or fulfilled by the contracting parties" (Cooke et al., 2004; 280) that are never explicitly written down. This can be the case of both contributions and inducements. Even if some job requirements clearly expressed, many are latent expectations that are seldom made explicit (Conway and Briner, 2005). Although extrinsic inducements, such as wages or holidays, tend to be formally reflected in the work contract, inducements can also be intangible, unwritten and mainly intrinsic (e.g. learning opportunities or meaningful work). In employment relations, some expectations, particularly regarding basic job demands (e.g. work hours) and rewards (e.g. wages), are made explicit in the work contract. Since in open source there are no formal written contracts all expectations are a matter of individual perceptions. Moreover, this distinct individual focus of PC theory adds nuance to open source studies drawing on social exchange theory. Indeed, the PC framework enables us to focus on individual contributors and their understandings and perceptions regarding how they contribute and what they get in return, rather than looking at the exchange itself, which would be the focus of social exchange theory.

Third, the PC enables to look at multiple relationships simultaneously (multi-foci approach). The literature suggests individuals develop various simultaneous psychological contracts with different agents [53]. These contracts are concurrent and although they are separate, they may be interrelated. For instance, the experience of psychological contract breach with one agent might influence the evolution of expectations towards other agents [54]. In the context of organizations, this multi-foci approach may include co-workers, trade unions, managers or clients [55] as separate agents that workers build psychological contracts with [53]. In the context of open source, it is likely that participants also develop multiple parallel psychological contracts with the project, the 
community, other developers or, when present, with any company involved. Whether or not this is the case, is an empirical question that is still to be explored.

Finally, these relationships evolve over time and the PC enables to capture that evolution. Employees continuously perceive and process messages sent by the organization, pertaining to obligations they owe their employer and to the incentives they will receive in return for fulfilling these obligations [56]. PC are thus constantly evolving on the basis of unfolding events and interpretations of these events. This intrinsic 'ongoingness' is a distinctive and essential part of their nature [44:32]. Contrary to self-determination theory which tends to assume the stability of motivations, the PC offers a dynamic account.

\section{Methodology}

\subsection{Case \& Data Collection}

To carry out this research, we have followed a case study design [57]. Following psychological contract research [56], we are interested in exploring how people understand and describe their exchange relationships.

For this reason, we have focused our attention on LibreOffice. LibreOffice is a fork of OpenOffice created after suffering from a community and project crisis when sponsor Sun Microsystems was acquired by Oracle. LibreOffice was started by core developers who were apprehensive of Oracle's implication. We chose this project for multiple reasons. First, the project involves both company employees and volunteer workers, likely holding different and even competing expectations. The Document Foundation which governs the project has employees, while attracting a large number of volunteers as well. Second, its history of company involvements may have left a lasting impression on the participants' articulation of expectations with regards to powerful actors. On the other hand, LibreOffice has been adopted by multiple public institutions. Third, because the fork of the source code would likely raise some issues to the surface through which we could gleam the existence of psychological contracts in participants. In so doing, we were hoping to showcase capacity of psychological contracts to theorize on why contributors stop participating. Finally, the project is established, leaving room for psychological contract evolution.

In particular, we collected and analyzed the discussion mailing list, amounting to more than 9000 pages from the years 2009--2013. Given the large dataset, we proceeded to identify relevant email threads through keyword search. Keywords related to contributions (e.g., responsibili*, dut*, demand*), inducements (e.g., motivat*, reward*, incentiv*), breach (e.g., disappoint*, betray*), fulfilment (e.g., pleased, grateful), and expectations in general (e.g., expect*, promis*, belie*). This resulted in 159 email threads to be coded in-depth.

\subsection{Data analysis process}

Mailing list analysis is a common investigative method in open source studies (e.g., [58]). A key advantage of studying mailing lists is that they allow us to place participants' accounts in context and to evaluate statements in relation to other actors who can agree or disagree on individuals' perceptions.

The coding process followed template analysis precepts [59]. In template analysis, data are coded using themes derived from a set of codes (i.e., the template). This list of codes can be derived from a number of sources, including the literature and theoretical frameworks. Other codes can be added into the template while coding progresses. In this sense, template analysis can be considered a combination of top-down and bottom-up coding [60].

The coding process involved multiple stages. First, the initial coding template was derived from the literature and the psychological contract theory. Second, the emails were read independently by two coders. Specialized mailing lists such as the developer list contained fewer references to psychological contract constructs and were discarded to focus on the discuss list. Taking into account the large dataset, we decided to code those threads containing emails that were relevant to the topic. The two coders analyzed these threads independently and the findings were later discussed and contrasted between the researchers. The coders held regular progress meetings to ensure consistency in their coding practices and develop a common template. Coding was done at the paragraph level with parallel coding [59]. The template was revised multiple times as the coding process went on, with a number of issues from the data pushing us to create new codes and sub-codes. For instance, the initial code 'inducements' was subdivided to reflect which agent they were expected from (e.g. the project, the developers or the users). The same happened for the code 'contributions'.

\section{Findings}

Participants' accounts do not only reveal their expectations regarding open source but also suggest why they keep volunteering for this work or why they stop doing so. The psychological contract emerges as a very useful theoretical lens to understand these processes. In particular, we observe that open source participants develop different psychological contracts 
with at least three types of agents and that can they experience breach with any one of them.

\subsection{Participation in open source through a psychological contract lens: entangled idiosyncratic contributions and inducements}

The analysis of the mailing lists indicates that participants develop a mental picture of what they expect to contribute and what inducements they expect to receive when participating in an open source project. These inducements and contributions are tied together and build an overall picture in participants' minds regarding what it means to be an open source participant. Some provide very specific accounts of such expectations, suggesting that in their minds, reciprocation is more than a vague idea of having future returns for their work. On the contrary their individual understanding of the exchange is often very concrete.

These inducements and contributions are tied in their narratives. For instance, when presenting his candidacy for the board of directors, one of them said:

"What motivates me to work for TDF? It is my firm belief that an independent, open, and meritocratic organization is the right home for a project the size, and the diversity, of LibreOffice. Being one of the founding members, I consider it my duty to help creating, shaping, and maintaining such an organisation."

LibreOffice discussion mailing list (2011)

This quote illustrates the participant's expectations and beliefs regarding his interaction with The Document Foundation, indicating that he expects to contribute by 'creating, shaping and maintaining' the organization. In exchange, he expects the organization to be 'independent, open, and meritocratic'. Another major actor in the community, running for the board of directors, described his psychological contract in the following terms:

"I've just tried to do what I know best: provide some marketing advice, and try to make TDF and LibreOffice as popular as possible by engaging the media. I have also gone a few miles around to represent TDF at conferences in Chicago, Zagreb and Athens, and I will also be speaking at LinuxCon Europe in Prague in October. What motivates me to work for TDF? I have a professional challenge: with a marketing budget of zero (in letters it looks bigger), outsmart corporations with a marketing budget with six or more zeros (and with a number in front which makes it more significant) (...) I promise that I will never write a single line of code (...) I will handle some marketing and media relations. I am also going to have an awful lot of fun"

\section{LibreOffice discussion mailing list (2011)}

His words underline that he does not see himself contributing with writing code but with other activities that support the project (such as marketing). In return for this work, he expects to be challenged and to have fun. Again, this exchange process is very specific suggesting that changes in inducements would have particular effects on the participant's contributions and vice versa. Participants do not hope for intangible undefined perks in exchange for a vague notion of contribution. They have a clear idea of what the exchange is supposed to be even if this idea is generally latent and not verbalized.

We also find evidence that the psychological contract developed by open source participants is idiosyncratic: each individual participant may develop a different one. Actual contributions and inducements are seldom spelled out. Therefore, there is ample room for participants to have different understandings of their exchange relationship. This is particularly salient when participants discuss certain specific inducements such as pay or membership. For instance, in one of the mailing lists a participant said:

"To me it is essential that the eco system is primarily kept intact by "real" volunteers... and that paid volunteers (sorry could not find a better expression) which have more time and resources are not taking over."

LibreOffice discussion mailing list (2013)

From this person's perspective, pay should not be a generalized inducement. In their minds, that is not part of the desirable exchange and may risk the project's identity. On the contrary, another participant stated:

"I *work* on LibreOffice. If I wasn't paid to do it, I doubt I would touch it"

LibreOffice discussion mailing list (2011)

This person does not only expect to be paid. He states that his participation is dependent on receiving this inducement and that, if this were not the case, he would likely withdraw from contributing. These contrasting quotes underline the importance of individual beliefs in developing exchange relationships. They also suggest that sooner or later, one of these participants will experience breach because their contrasting expectations cannot be simultaneously met. Different psychological contracts and the emergence of breach can thus explain why certain people continue participating while others do not. 


\subsection{Multi-foci psychological contracts}

We find that individuals create expectations regarding their relationships with a variety of actors involved in open source projects. In particular, participants develop parallel psychological contracts with the project (i.e. the Foundation), the community of developers and the users. These psychological contracts entail different expectations regarding contributions and inducements. Table 1 presents examples of quotes that illustrate the contents of the psychological contracts developed with each of these agents and examples of how inducements and contributions are exchanged in the minds of participants for each of them.

The quotes in Table 1 underline that open source participants develop a network of expectations, promises and obligations with a variety of agents who are involved in the process of creating open source software. These relationships can potentially affect the sustainability of individual participation in different ways because they entail that psychological contract breach can happen at different levels.

Table 1: Illustrative quotes of multi-foci psychological contract in open source

\begin{tabular}{|c|c|c|c|}
\hline & Contributions & Inducements & Exchange \\
\hline $\begin{array}{l}\text { The project / } \\
\text { Foundation }\end{array}$ & $\begin{array}{l}\text { "If you look at what is in the } \\
\text { email and the wiki page I } \\
\text { believe you will see that } \\
\text { translating is most certainly } \\
\text { considered contributing. } \\
\text { Same is true for working a } \\
\text { LibreOffice booth at a fair } \\
\text { or linux fest." }\end{array}$ & $\begin{array}{l}\text { "If a third party attempted to sue } \\
\text { You for (say) some violation of } \\
\text { their copyright, then the } \\
\text { Foundation can step in and say } \\
\text { "we are responsible. Bernhard } \\
\text { was acting according to our } \\
\text { wishes. sue us, not him." The } \\
\text { theory is that a judge will then } \\
\text { remove you from the case, and } \\
\text { put Apache in there." }\end{array}$ & $\begin{array}{l}\text { "I am willing to setup a task on } \\
\text { Bounty Source and chip in } \$ 100 \text {, } \\
\text { but maybe TDF can consider to } \\
\text { donate a new laptop to a } \\
\text { volunteer who promises to work } \\
\text { on the issues? Someone donated } \\
\text { hardware to a Gnome developer } \\
\text { and they got some fixes into } 3.10 \\
\text { because of it." }\end{array}$ \\
\hline $\begin{array}{l}\text { Community } \\
\text { of } \\
\text { developers }\end{array}$ & $\begin{array}{l}\text { "I have a problem when } \\
\text { it comes to rewarding } \\
\text { people that refuse to make } \\
\text { an effort to learn. Notice, I } \\
\text { said "refuse", not } \\
\text { "incapable of" }\end{array}$ & $\begin{array}{l}\text { "It is therefore by design (...), } \\
\text { that contribution to LibreOffice } \\
\text { is rewarded, e.g. by being } \\
\text { empowered to decide on } \\
\text { directions or designs or code, } \\
\text { vote for various things including } \\
\text { the board, etc." }\end{array}$ & $\begin{array}{l}\text { "Membership in the community is } \\
\text { based on merit." }\end{array}$ \\
\hline Users & $\begin{array}{l}\text { "You don't want to take any } \\
\text { chances with data or } \\
\text { formatting loss, it's the duty } \\
\text { of programmers to } \\
\text { warn/protect users against } \\
\text { risky behaviours" (2011) }\end{array}$ & $\begin{array}{l}\text { "I don't see why you would } \\
\text { expect a 'users first' approach } \\
\text { to change current processes } \\
\text { significantly. BUT, in my view } \\
\text { there is a considerable potential } \\
\text { upside because it will make the } \\
\text { user feel more valued, it will } \\
\text { make the step to deeper } \\
\text { involvement seem smaller (...), } \\
\text { and it will probably make it } \\
\text { slightly more likely that users } \\
\text { will take that step, which is what } \\
\text { we all want" }\end{array}$ & $\begin{array}{l}\text { "Users are users. They get rights } \\
\text { from the software freedom } \\
\text { conveyed by the licenses we use. } \\
\text { They do not get anything else, } \\
\text { unless they want to become } \\
\text { contributors. Anything else is } \\
\text { toxic for the community and } \\
\text { profoundly demotivational" }\end{array}$ \\
\hline
\end{tabular}

\subsection{Experiences of psychological contract breach in open source}

Breach happens when participants feel their expectations are unfulfilled. This can take place for any of the above-described psychological contracts (see table 1). Sometimes, participants will feel the psychological contract with the project has been broken. In the analyzed case, this was particularly salient when a firm got involved in the project. As a result, many participants voiced concern over either not expecting to contribute towards the interests of a for profit organization known for its closed source practices or over disappointment with expected inducements. For instance, a participant described his intention to withdraw from the project after a firm got involved in the following terms:

"Any further contribution to that project has really no sense from a (...) volunteer's point of view (...) a 
direct contribution to Apache Ooo is rather risky ("I give you something and... ehi, you have no duty to give me something back!! (...) That isn't, really what I want from a *free software* project. Plain and simple (-)" LibreOffice discussion mailing list (2011)

Breach can also take place at the users' or the developers' levels. One of the generally expected inducements is the respect of the community. When participants feel their interactions with others do not show such respect, they can feel disappointed and as a result, decreased their involvement in the project. One of the participants' accounts illustrates this type of breach:

"I'm shocked that a Discuss topic where 54 messages from many people (several of them opposing and presenting valid arguments against) was totally dismissed because someone decided that it was time to change and the main argument was that "it was outdated". (...) Communities don't behave like this. (Disappointed)"

LibreOffice discussion mailing list (2012)

The findings also indicate that unfulfillment can sometimes be related to the participants' perceived inability to meet their expected contributions, rather than about unmet inducement. A participant described how he was abandoning the project because he felt his contribution, given his personal life responsibilities, was not at his expected level.

"After quite an amount of time and a lot of work (...) I have to tell you that I'll have to stop my activities in this great community. Even if I tried not to compromise my real life by my LibreOffice activities, I had to realize, that I can't reach this goal (...). LibreOffice activities have ever been fun, rewarding and challenging - improving my skills (not only my English) and giving back appreciation that showed me that my work is important to the community. It's hard to step back and let you work on your own."

LibreOffice discussion mailing list (2011)

When experiencing breach at any level, participants may stop contributing towards the project, community or the users, or reduce their contributions to align them more fairly with the inducements they feel they receive.

\section{Discussion}

SDT theories focus on why people participate but cannot tell us much about why they stop or change how much they participate. In this paper, we have followed studies that proposed social exchange mechanisms to explain why and how people take those decisions. In particular, we have relied on the psychological contract to argue that sustained participation depends on the perceived balance between inducements and contributions, rather than just rewards. By re-centering the participant as an individual in relation with other actors, we have a better idea of the complex ecosystem of actors that are involved in the decision to continue participating or stop doing so.

Even if the PC lens has been primarily used to explore employment relationship, our study suggests it can shed light over the behaviors of open source participants who are not employees of the project. This finding is relevant for the growing literature on the digitized economy, which suggests that work that was traditionally carried out by full-time employees is now in the hands of "a crowd of individual entrepreneurs and on-demand workers" [61:7]. The case of open source participants is often used as an example of new forms of digitized independent work [5]. The PC therefore seems a pertinent theoretical lens to expand knowledge on this growing stream of workers and how they behave.

The findings highlight that open source participants develop simultaneous psychological contracts with various significant agents. These multifoci psychological contracts [53], can have different roles in the participants' decision to stay engaged with the project. The literature points out that the multiplicity of expectations and obligations might create tensions and contradictions that participants have to process [62].

The concept of breach emerges as key. It helps us infer about the possible evolutions of relationships. On the one hand, an individual might experience a breach with one actor or one kind of actor (e.g., the project), but not with others (e.g., new developers, but not core developers). In this case, psychological contracts between different actors can be seen as independent from one another.

On the other hand, for other participants, a breach with one actor can affect their behavior towards other participants [54]. This is because the PCs can be interlinked. Further research should explore the extent to which different levels of breach entail different behaviors from participants and which ones are most salient in explaining them deciding to stop participating. Moreover, often, breach does not always result in complete withdrawal. It can also lead to reduced contributions or, sometimes to unsocial behaviors. Do what extent this is the case in open source and may influence the sustainability of a project also requires further exploration. 
Finally, the literature suggests that psychological contracts evolve over time. The open source literature also suggests that roles change as projects mature [36], which may influence the contents of participants psychological contracts.

\subsection{Practical contributions}

This paper's findings suggest a key practical implication. Understanding the relational complexity of individual experiences involved in decisions to continue or stop participation can help code maintainers evaluate their work processes. There is a growing willingness and preoccupation among the open source community to be able to measure and reward open source work fairly (e.g., make visible documentation contributors). Seeing sustained participation from a psychological contract perspective could help define community and work metrics that better take into account participant contributions and propose commensurate inducements.

In addition, the idea that contributors develop different psychological contracts with different parties indicates that managing the sustainability of open source projects is not just about the project and the contributors, but about the expectations the latter develop with a multiplicity of actors and that such expectations may influence one another.

\section{Limitations and conclusion}

These findings may be limited by the specificities of the analyzed case. In addition, although the dataset is very large, it was generated a decade ago and the actual proportion of relevant threads we could study is limited. This is because participants discuss many different topics in the mailing lists which are often not related to how they see their contributions to the project. While the mailing lists provide interesting unprompted insights regarding contributors' psychological contracts, further research should deepen the findings presented in this paper by delving into their narratives regarding their participation. Such an approach would require using a diversity of data collection methods (e.g., in-depth interviews). In addition, the method did not allow us to identify individual characteristics of contributors. The proposed use of additional data collection methods would also provide information on elements such as expertise, cultural background, or type of employment.

Notwithstanding these limitations, this paper makes two key contributions. First, the analysis of the LibreOffice case has shed light on how individual open source contributors understand their participation and how they develop a myriad of expectations with multiple actors, that influence their decision to participate or to stop participating. When expectations regarding contributions and inducements are unmet, contributors may experience psychological contract breach which may trigger them to quit. This finding is useful for those hoping to develop online communities in general. Understanding and managing participants' expectations is thus key to making such communities sustainable. Second, the paper shows that PC theory is a valid lens to explore the phenomenon of open source participation and a fruitful avenue for future research.

\section{References}

[1] Mindel, V., L. Mathiassen, and A. Rai, "The Sustainability of Polycentric Information Commons", MIS Quarterly 42(2), 2018, pp. 607-A14.

[2] RedHat, The State of Enterprise Open Source: A Red Hat Report, 2021. 2021.

[3] OpenUK, State of Open: The UK in 2021, OpenUK,

[4] Nagle, F., Government Technology Policy, Social Value, and National Competitiveness, Harvard Business School, Rochester, NY, 2019.

[5] Scholz, T., Platform Cooperativism. Challenging the Corporate Sharing Economy, Rosa Luxembourg Stiftung, New York, NY, USA, 2016.

[6] Benkler, Y., The wealth of networks: How social production transforms markets and freedom, Yale University Press, 2006.

[7] Ke, W., and P. Zhang, "Motivations in Open Source Software Communities: The Mediating Role of Effort Intensity and Goal Commitment", International Journal of Electronic Commerce 13(4), 2009, pp. 39-66.

[8] Lerner, J., and J. Tirole, "Some Simple Economics of Open Source", Journal of Industrial Economics 50(2), 2002, pp. 197-234.

[9] Bonaccorsi, A., and C. Rossi, "Comparing motivations of individual programmers and firms to take part in the open source movement: From community to business", Knowledge, Technology \& Policy 18(4), 2006, pp. $40-64$.

[10] Ostrom, E., and C. Hess, "A Framework for Analyzing the Knowledge Commons", In C. Hess and E. Ostrom, eds., Understanding Knowledge as a Commons: From Theory to Practice. Library Publications, 2007.

[11] Midha, V., and A. Bhattacherjee, "Governance practices and software maintenance: A study of open source projects", Decision Support Systems 54(1), 2012, pp. 23-32.

[12] Maruping, L.M., S.L. Daniel, and M. Cataldo, "Developer Centrality and the Impact of Value Congruence and Incongruence on Commitment and Code Contribution Activity in Open Source Software Communities", MIS Quarterly 43(3), 2019, pp. 951-A7.

[13] Fang, Y., and D. Neufeld, "Understanding Sustained Participation in Open Source Software Projects", 
Journal of Management Information Systems 25(4), 2009, pp. 9-50.

[14] Benbya, H., and N. Belbaly, "Understanding Developers' Motives in Open Source Projects: A MultiTheoretical Framework", 2010.

[15] Dong, J.Q., W. Wu, and Y. (Sarah) Zhang, "The faster the better? Innovation speed and user interest in open source software", Information \& Management 56(5), 2019, pp. 669-680.

[16] Daniel, S., S. Janansefat, E.I. Diamant, and Y. Ren, "Single- and Double-Loop Learning: Linking Free/Libre Open Source Software (FLOSS) Developer Motivation, Contribution, and Turnover Intentions", ACM SIGMIS Database: the DATABASE for Advances in Information Systems 51(4), 2020, pp. 68-92.

[17] Shah, S.K., "Motivation, Governance, and the Viability of Hybrid Forms in Open Source Software Development", Management Science 52(7), 2006, pp. 1000 1014.

[18] Ye, Y., and K. Kishida, "Toward an Understanding of the Motivation Open Source Software Developers", Proceedings of the 25th International Conference on Software Engineering, IEEE Computer Society (2003), 419429.

[19] Ghosh, R., "Understanding free software developers: Findings from the FLOSS study", Perspectives on Free and Open Source Software, 2005.

[20] David, P.A., and J.S. Shapiro, "Community-based production of open-source software: What do we know about the developers who participate?", Information Economics and Policy 20(4), 2008, pp. 364-398.

[21] Hann, I.-H., J.A. Roberts, and S.A. Slaughter, “All Are Not Equal: An Examination of the Economic Returns to Different Forms of Participation in Open Source Software Communities", Information Systems Research 24(3), 2013, pp. 520-538.

[22] Roberts, J.A., I.-H. Hann, and S.A. Slaughter, "Understanding the Motivations, Participation, and Performance of Open Source Software Developers: A Longitudinal Study of the Apache Projects", Management Science 52(7), 2006, pp. 984-999.

[23] Ke, W., and P. Zhang, "The Effects of Extrinsic Motivations and Satisfaction in Open Source Software Development.", Journal of the Association for Information Systems 11(12), 2010, pp. 784-808.

[24] Alexy, O., and M. Leitner, "A Fistful of Dollars: Are Financial Rewards a Suitable Management Practice for Distributed Models of Innovation?", European Management Review 8(3), 2011, pp. 165-185.

[25] Krishnamurthy, S., "On the intrinsic and extrinsic motivation of free/libre/open source (FLOSS) developers", Knowledge, Technology \& Policy 18(4), 2006, pp. 17-39.

[26] Terranova, T., "Free Labor: Producing Culture for the Digital Economy", Social Text 18(2), 2000, pp. 33-58.

[27] Barron, A., "Free software production as critical social practice", Economy and Society 42(4), 2013, pp. 597625.

[28] Gamalielsson, J., and B. Lundell, "Sustainability of Open Source software communities beyond a fork: How and why has the LibreOffice project evolved?", Journal of Systems and Software 89, 2014.
[29] Lakhani, K., and R. Wolf, "Why hackers do what they do: Understanding motivation and effort in free/open source software projects", In J. Feller, B. Fitzgerald, S. Hissam and K. Lakhani, eds., Perspectives on Free and Open Source Software. The MIT Press, 2005, 3--21.

[30] O'Mahony, S., "Guarding the commons: how community managed software projects protect their work", Research Policy 32(7), 2003, pp. 1179-1198.

[31] Raymond, E.S., The Cathedral and the Bazaar: Musings on Linux and Open Source by an Accidental Revolutionary, O’Reilly Media, 2001.

[32] Osterloh, M., and S. Rota, "Open source software development - Just another case of collective invention?", Research Policy 36(2), 2007, pp. 157-171.

[33] Ostrom, E., Governing the Commons: The Evolution of Institutions for Collective Action, Cambridge University Press, Cambridge ; New York, 1990.

[34] Widlok, T., Anthropology and the Economy of Sharing, Routledge, Abingdon, Oxon; New York, NY, 2016.

[35] von Krogh, G., S. Spaeth, and K.R. Lakhani, "Community, joining, and specialization in open source software innovation: a case study", Research Policy 32(7), 2003, pp. 1217-1241.

[36] O'Mahony, S., and F. Ferraro, "The Emergence of Governance in an Open Source Community", Academy of Management Journal 50(5), 2007, pp. 1079-1106.

[37] von Hippel, E., and G. von Krogh, "Open Source Software and the 'Private-Collective' Innovation Model: Issues for Organization Science", Organization Science 14(2), 2003, pp. 209-223.

[38] Setia, P., B. Bayus, and B. Rajagopalan, "The Takeoff of Open Source Software: A Signaling Perspective Based on Community Activities", Management Information Systems Quarterly 44(3), 2020, pp. 1439-1458.

[39] March, J.G., and H.A. Simon, Organizations, John Wiley \& Sons, Rochester, NY, 1958.

[40] Rousseau, D.M., Psychological Contracts in Organizations: Understanding Written and Unwritten Agreements, SAGE Publications, Inc, Thousand Oaks, 1995.

[41] Rousseau, D.M., "Psychological and implied contracts in organizations", Employee Responsibilities and Rights Journal 2(2), 1989, pp. 121-139.

[42] Rousseau, D.M., and K.A. Wade-Benzoni, "Linking strategy and human resource practices: How employee and customer contracts are created", Human Resource Management 33(3), 1994, pp. 463-489.

[43] Kelloway, E.K., D.G. Gallagher, and J. Barling, "Work, Employment, and the Individual", In B.E. Kauffman, ed., Theoretical Perspectives on Work and the Employment Relationship. Cornell University Press, Ithaca, NY, 2004.

[44] Conway, N., and R.B. Briner, Understanding Psychological Contracts at Work: A Critical Evaluation of Theory and Research, OUP Oxford, 2005.

[45] Bateman, T.S., and D.W. Organ, "Job Satisfaction and the Good Soldier: The Relationship Between Affect and Employee 'Citizenship"', Academy of Management Journal 26(4), 1983, pp. 587-595. 
[46] Cañibano, A., "Workplace flexibility as a paradoxical phenomenon: Exploring employee experiences", Human Relations 72(2), 2019, pp. 444-470.

[47] Kalleberg, A.L., and T. Reve, "Contracts and Commitment: Economic and Sociological Perspectives on Employment Relations", Human Relations 46(9), 1993, pp. 1103-1132.

[48] Ryan, R.M., and E.L. Deci, "Intrinsic and Extrinsic Motivations: Classic Definitions and New Directions", Contemporary Educational Psychology 25(1), 2000, pp. 5467.

[49] Simon, H.A., Administrative behavior. Second edition., Macmillan Co., New York, N.Y., 1957.

[50] Seeck, H., and M. Parzefall, "Employee agency: challenges and opportunities for psychological contract theory", Personnel Review 37(5), 2008, pp. 473-489.

[51] Morrison, E.W., and S.L. Robinson, "When employees feel betrayed: a model of how psychological contract violation develops", Academy of Management Review 22(1), 1997, pp. 226-256.

[52] Cornford, T., M. Shaikh, and C. Ciborra, "Hierarchy, Laboratory and Collective: Unveiling Linux as Innovation, Machination and Constitution.", Journal of the Association for Information Systems 11(12), 2010, pp. 809837.

[53] Marks, A., "Developing a multiple foci conceptualization of the psychological contract", Employee Relations 23(5), 2001, pp. 454-469.

[54] Alcover, C.-M., R. Rico, W.H. Turnley, and M.C. Bolino, "Multi-dependence in the formation and development of the distributed psychological contract", European Journal of Work and Organizational Psychology 26(1), 2017, pp. 16-29.

[55] Boshoff, C., and G. Mels, "The Impact of Multiple Commitments on Intentions to Resign: an Empirical Assessment", British Journal of Management 11(3), 2000, pp. $255-272$.

[56] Tietze, S., and S. Nadin, "The psychological contract and the transition from office-based to home-based work", Human Resource Management Journal 21(3), 2011, pp. 318-334.

[57] Yin, R., Case Study Research - Design and Methods, Sage, 2003.

[58] Shaikh, M., and E. Vaast, "Folding and Unfolding: Balancing Openness and Transparency in Open Source Communities", Information Systems Research 27(4), 2016, pp. 813-833.

[59] King, N., "Using templates in the thematic analysis of text", In C. Cassel and G. Symon, eds., Essential Guide to Qualitative Methods in Organizational Research. Sage Publications, London, 2004, 256-270.

[60] Dey, I., Qualitative Data Analysis: A User-Friendly Guide, Routledge, New York, NY, 10001, 1993.

[61] Sundararajan, A., "The Future of Work", Finance \& Development 2017. https://www.imf.org/external/pubs/ft/fandd/2017/06/sundar arajan.htm

[62] Wade-Benzoni, K.A., D.M. Rousseau, and M. Li, "Managing relationships across generations of academics: Psychological contracts in faculty-doctoral student collaborations", International Journal of Conflict Management 17(1), 2006, pp. 4-33. 